\title{
Redução do percentual de austenita retida pelo processo de shot peening
}

\author{
Decrease in austenite retained percentage \\ by shot peening process
}

Marcelo Gautério Fonseca ${ }^{1}$, Jorge Luis Braz Medeiros ${ }^{1}$ Leandro Macedo Cozza ${ }^{2}$, Sérgio da Silva Cava ${ }^{2}$,

\author{
${ }^{1}$ Laboratório de Ensaios Mecânicos, PPMEC/EE/FURG. Avenida Itália, Km 8, Bairro Carreiros, CEP: 96203-900, Rio \\ Grande, RS, Brasil \\ ${ }^{2}$ Laboratório de Crescimento de Cristais Avançados e Fotônica, PPGCEM/CDTEC/UFPEL, Rua Gomes Carneiro, 01, \\ Centro. CEP: 96010-610, Pelotas, RS , Brasil \\ e-mail: marcelofonseca@furg.br, jorge.braz@furg.br, lcozza@bol.com.br, sergiocava@gmail.com
}

\begin{abstract}
RESUMO
O avanço tecnológico sugere o desenvolvimento de novos materiais e novas tecnologias que possam proporcionar produtos competitivos economicamente e com as propriedades mecânicas desejadas. Durante o processo de cementação e posterior têmpera o material sofre uma transformação, passando de uma estrutura austenítica para martensitica. Essa transformação geralmente não é completa devido a estabilização do carbono e outros elementos de liga, restando uma fase residual de austenita. Este componente degrada as propriedades mecânicas do aço, provocando alterações dimensionais e diminuição em sua resistência mecânica. Para limitar a presença da austenita retida, além de processos de conformação mecânica, o revenimento é um dos tratamentos térmicos mais empregados. Estes métodos exigem equipamentos de elevado custo, procedimentos complexos e elevadas incertezas nos resultados. Neste contexto surge como alternativa o processo de tratamento superficial através de shot peening a fim de melhorar as propriedades mecânicas na superfície dos metais. Diante do exposto este trabalho tem como objetivo desenvolver uma técnica confiável para redução do percentual de austenita retida em martensita, melhorando o desempenho de componentes cementados. Para tal foi realizada a cementação de uma amostra de aço para aplicação dos processos de shot peening dinâmico e estático e posterior análise microestrutural e de microdureza. Os resultados indicaram que a aplicação dos processos mecânicos de shot peening se apresentou com uma técnica confiável para transformação da austenita retida em martensita, melhorando o desempenho de componentes cementados. Dentre estes processos o de shot peening estático foi o que apresentou melhor rendimento com valores de percentual de austenita retida de $6,04 \%$ e microdureza de $92 \mathrm{HV}$. Os resultados são coerentes com os encontrados na literatura e contribuem para que esta técnica possa ser utilizada no intuito de proporcionar um material com menor índice de falha.
\end{abstract}

Palavras-chave: Aço DIN 20MnCr5. Carbonitretação. Jateamento de microesferas.

\section{ABSTRACT}

The technological advancement suggests the development of the new materials and technologies that can be supply economically competitive products and with the desired mechanical properties. During the carburizing process and quenching the material undergoes a transformation from that austenitic for the martensitic structure. This transformation is generally not full due of the carbon stabilization and other alloy elements result in the austenite residual phase. This component destroys the mechanical properties of steel causing dimensional changes and decreasing in its mechanical strenght. For the limit the presence retained austenite, moreover of the mechanical forming process, the tempering is one of the most used heat treatments. These methods require expensive cost equipments, complex procedures and high uncertainties in the results. In the context the superficial treatment process trought the shot peening appears as a alternative to improve the mechanical properties in the surface of the metals. Given the above that this paper aims to develop a reliable technique for the decreasing the percentage retide austenite in the martensite improving the performance of 
cemented componentes. To this end, the steel sample was realized the carburing of for the application of the dinamic and static shot peening process and microstructutal and microhardness analisys. The results indicated that the application of the shot peening mechanical process performed with the reliable technique for the transformation from retide austenite for the martensite, improving the performance of the cemented components. Among these processo the static shot peening was the presented the best performance with the retained austenite porcentage values of $6,04 \%$ and microhardness of $92 \mathrm{HV}$. The results are consistents with the those found in the literature and contribute for that technique can be used in order to provide the material with minor failure rate.

Keywords: DIN 20MnCr5 steel. Carbonitriding. Shot blasting microspheres.

\section{INTRODUÇÃO}

$\mathrm{O}$ avanço tecnológico sugere o desenvolvimento de novos materiais e novas tecnologias que possam proporcionar produtos competitivos economicamente e com as propriedades desejadas para as mais diversas aplicações. Durante o processo de tratamento termoquimico de cementação e posterior têmpera o material sofre uma transformação, passando de uma estrutura austenítica para outra, onde predomina a martensita. Essa transformação geralmente não é completa devido a estabilização que o carbono e outros elementos de liga ocasionam no material, restando, nos espaços entre as ripas e placas da martensita, uma fase residual de austenita retida. Este componente indesejado degrada as propriedades mecânicas do aço temperado, provocando alterações dimensionais e diminuição em sua dureza e resistência mecânica. Para diminuir a presença da austenita retida, além de processos de conformação mecânica, o revenimento é um dos tratamentos térmicos mais empregados. Estes métodos exigem equipamentos de elevado custo, procedimentos complexos, e elevadas incertezas nos resultados, principalmente na determinação de pequenas frações desta componente.

Neste âmbito há algumas formas de se transformar esta austenita retida em martensita, dentre elas o processo de tratamento superficial através de shot peening surge como alternativa com a finalidade de melhorar as propriedades mecânicas na superfície dos metais. Em tal processo as colisões das microesferas com a superfície da peça proporcionam energia mecânica suficiente para que ocorra a transformação da austenita retida em martensita, dependendo da intensidade da carga aplicada esta transformação poderá ocorrer por deformação elástica (martensita de tensão) e deformação plástica (martensita de deformação) [1].

$\mathrm{O}$ processo de cementação consiste em se adicionar uma quantidade de carbono à superfície da peça na faixa de $0,8 \%$ e $1 \%$ a uma temperatura entre 850 e $950{ }^{\circ} \mathrm{C}$. Estas temperaturas podem ser mais elevadas a fim de se reduzir o tempo de cementação ou produzir profundidades de camada cementadas mais profundas na peça. Este tratamento termoquímico de introdução do carbono na austenita é diretamente influenciado por dois processos que determinam a taxa de cementação. Estes são a absorção do carbono na superfície e a difusão do carbono pelo aço. A cementação e amplamente utilizada na produção de peças e componentes para suportarem escorços de tração, flexão, torção e resistência a fadiga [2- 4].

Na obtenção de aços cementados o processo de difusão ocorre da superfície para o núcleo, formando um sistema microestrutural complexo. Diferentes microestruturas e possíveis mudanças dependem do tratamento térmico realizado após a cementação. A microestrutura da camada cementada consiste basicamente de martensita, austenita retida, carbonetos, inclusões, segregações de fósforo e óxidos na camada cementada [5].

Dependendo da velocidade de resfriamento do aço-carbono, podem-se obter diferentes composições das fases presentes no tratamento, como perlita, bainita e a martensita. A temperatura de austenização pode variar com a composição química de cada material, o objetivo no processo é conduzir o aço a uma fase, na qual se obtém o melhor arranjo possível dos cristais do aço, para obter a futura dureza. Após essa fase o aço pode ser submetido a outros tratamentos térmicos suplementares envolvendo outras transformações de fases, de acordo com a necessidade. Cada aço tem uma temperatura de austenização, e que é aquela que proporciona a máxima dureza. A segunda etapa da têmpera é o tempo de resfriamento, A rapidez do resfriamento é importante para formação da estrutura desejada [6].

A transformação da austenita em martensita não depende do tempo, mas, sim do grau de resfriamento, após a têmpera, pode-se ter à temperatura ambiente certa quantidade de "austenita retida" ou "austenita residual" que degrada as propriedades mecânicas dos aços temperados e ainda, ao se transformar posteriormente, pode ocasionar o fenômeno de instabilidade [7]. A austenita retida surge após a solubilização e tempera, tendo como sua principal causa a composição química e o elemento mais importante o carbono, o qual rebaixa significativamente o início e o fim da formação da martensita. O carbono em solução sólida contribui aumentando a resistência ao cisalhamento da austenita, desse modo, quantidades apreciáveis de austenita não transformada, podem estar presentes entre as ripas de martensita a temperatura ambiente. Já independente de quaisquer níveis carbono, os elementos de liga tendem a estabilizar a austenita, favorecendo o aumentando nos percentuais de austenita retida [8]. Outro fator que influi nos percentuais de austenita retida é a tempera- 
tura de austenização, quanto maior for a mesma, maior será a capacidade de dissolver excessos de carbonetos na austenita, antes do resfriamento [9].

Nos processos de tratamento térmico aplicado como tempera entre outros, a transformação da austenita não é completa, permanecendo uma fração de austenita retida metaestável a temperatura ambiente de forma não desejada, sua transforma para martensita pode ser estimada pela temperatura na qual ela pode ser transformada, tanto por resfriamento quanto por deformações oriundas de solicitações mecânicas [10, 11].

O Shot Peening é muito utilizado para melhorar da vida a fadiga, mas investigações realizadas em uma grande variedade de materiais apontam que tal processo também pode reduzir atrasar ou evitar outros tipos de problemas como fretting, corrosão por fadiga e fragilização por hidrogênio [12]. Seu princípio de funcionamento consiste em um jateamento de microesferas em alta velocidade contra a superfície de peças, componentes de máquinas ou elementos estruturais, o impacto das microesferas ou granalhas promovem uma deformação na superfície do material causando uma camada com tensões residuais de compressão. Porém, camadas internas mais profundas abaixo da superfície deformada plasticamente, encontram-se dentro de um regime elástico não conseguindo retornar a sua geometria original, permanecendo, como consequência, com deformação elástica remanescente. É desta maneira que se originam as tensões residuais de compressão como resultado da interação entre estas duas camadas, superficial e interna [13].

Para obtenção das características e propriedades mecânicas desejadas como rugosidade da superfície, dureza da superfície e tensões residuais e taxas de deformação envolvidas no processo é importante determinarmos as variáveis envolvidas como a pressão do ar, diâmetro das microesferas, taxa de alimentação, tempo de processo e distância do bico até a superfície que será tratada. Outras variáveis com geometria da peça e ângulo de impacto são de extrema relevância no processo, por definição é de $90{ }^{\circ} \mathrm{C}$, quanto menor for o ângulo de colisão da esfera com a superfície da peça menor será a intensidade do shot peening, devendo ser compensado variando a intensidade tamanha da microesfera ou alterando outras variáveis para que se possa obter as deformações adequadas [13].

Existem dois métodos convencionais de shot peening. O primeiro método envolve a aceleração de partículas de materiais com ar comprimido, em um fluxo de ar de alta velocidade podendo atingir até 76,2 $\mathrm{m} / \mathrm{s}$. O segundo método envolve a aceleração de partículas por meio de uma turbina rotativa centrifuga.

No processo de shot peening as colisões das microesferas com a superfície da peça proporcionam energia mecânica suficiente para que ocorra a transformação da austenita retida em martensita, dependendo da intensidade da carga aplicada esta transformação poderá ocorrer por deformação elástica (martensita de tensão) e deformação plástica (martensita de deformação) [1].

Diante do exposto este trabalho tem como objetivo desenvolver uma técnica confiável para redução do percentual de austenita retida em martensita, melhorando o desempenho de componentes cementados. Para isto se verificará a presença de austenita retida no processo de shot peening através de análise de imagens da microestrutura e do perfil de microdurezas.

\section{MATERIAIS E MÉTODOS}

\subsection{Materiais}

O material utilizado neste trabalho foi o aço DIN 20MnCr5 que devido sua composição química é classificado como aços para cementação e/ou carbonitretação, possuindo média temperabilidade de núcleo. A Figura 1 apresenta a amostra do material pesquisado neste artigo.

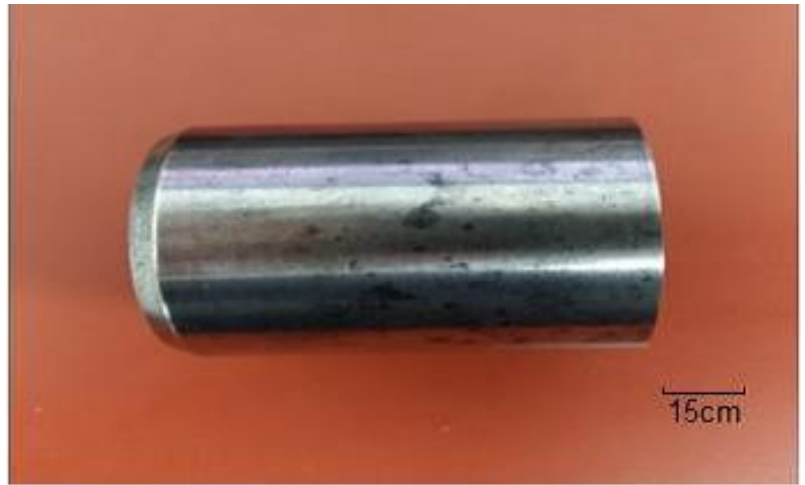

Figura 1: Material cementado a partir do qual foram retirados os corpos de prova. 


\subsection{Processo de cementação}

Para possibilitar o processo de verificação da austenita retida, o aço utilizado foi cementado em atmosfera a base de Metanol e Propano por 12 horas de cementação com potencial de carbono 1,2\%, e temperatura de $925^{\circ} \mathrm{C}$.

\subsection{Tratamento térmico}

Realizada têmpera direta em óleo acelerado Houghton $\mathrm{KB}\left(110^{\circ} \mathrm{C} / \mathrm{s}\right)$ com posterior processo de revenimento a temperatura de $180^{\circ} \mathrm{C}$.

\subsection{Preparação dos corpos de prova (CP)}

Após a cementação e o tratamento térmico foram seccionados três corpos de prova por corte (abrasão). Os corpos de prova ficaram divididos em:

a) $1^{\circ} \mathrm{CP}$ : utilizado como referência;

b) $2^{\circ} \mathrm{CP}$ : utilizada no processo de shot peening dinâmico;

c) $3^{\circ} \mathrm{CP}$ : utilizada no processo de shot peening estático.

Para cada CP foram retiradas tréplicas para análise microestrutural e microdureza. A Figura 2 apresenta um dos corpos de prova no suporte de proteção do porta amostra para realização do shot peening.

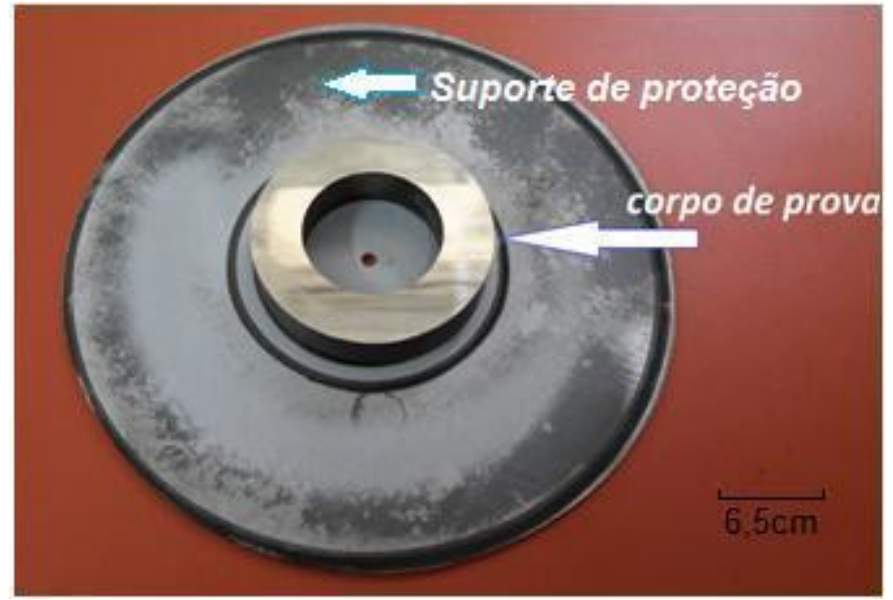

Figura 2: Fixação do corpo de prova no suporte .

\subsection{Shot peening dinâmico}

Neste processo foi utilizado o método que envolve a aceleração de partículas de materiais com ar comprimido, em um fluxo de ar de alta velocidade enquanto o porta amostra com o corpo de prova rotacionava em torno do seu próprio eixo. Para isto foi utilizado o equipamento disponível na Universidade Federal do Rio Grande com os seguintes parâmetros de controle:

- Tipo de microesfera: microesfera de vidro impacto C da (Zirtec) peneira 150-250.

- Vazão de operação: 0,29 L/min.

- Distância do bico ao material: 2,5 mm

- Tempo de shot peening: $17 \mathrm{~min}$

- Rotação utilizada: 6 rpm

Na Figura 3, é apresentada o corpo de prova no porta amostra para realização do shot peening dinâmico. 


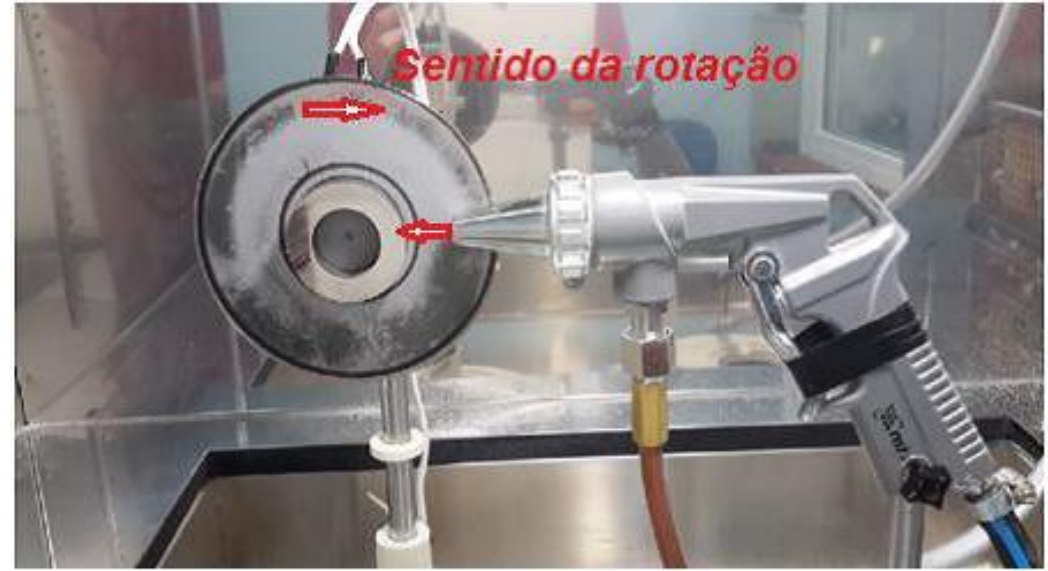

Figura 3: Parte do equipamento responsável pelo shot peening dinâmico.

\subsection{Shot peening estático}

Para a realização deste processo foi utilizado o mesmo método citado no item 2.5, porém com o corpo de prova estático. Os parâmetros do equipamento são os mesmos com exceção da velocidade de rotação que neste caso não é aplicável.

\subsection{Análise da microestrutura e do percentual de austenita retida}

Com as análises das imagens de microestrutura pode-se avaliar microconstituintes, presença de trincas e determinação dos percentuais de austenita retida. Para isto foram utilizadas imagens através do programa Phase Analysis utilizando Microscópio Óptico (MO) Modelo GX51F, série 0F68306, Olympus e Microscópio Eletrônico de Varredura (MEV), em modo alto e baixo vácuo, Jeol, JSM - 6610LV.

\subsection{Ensaio de microdureza}

Este ensaio teve como intuito verificar a variação da microdureza superficial após o tratamento mecânico. Para tal foi realizado os testes de microdureza com carga de $300 \mathrm{~g}$ pelo período de 10 segundos e os intervalos utilizados foram de $0,05 \mathrm{~mm}$ da superfície cementada e posteriormente de 0,1 até $2,5 \mathrm{~mm}$ de profundidade da mesma superfície. Os testes foram realizados em microdurômetro, modelo hwt-2t, série 163034901552, Shimadzu.

\section{RESULTADOS}

\subsection{Análise microestrutural das amostras após cementação e tratamento térmico}

A Figura 4 apresenta a microestrutura da camada cementada constituída por martensita e austenita retida.

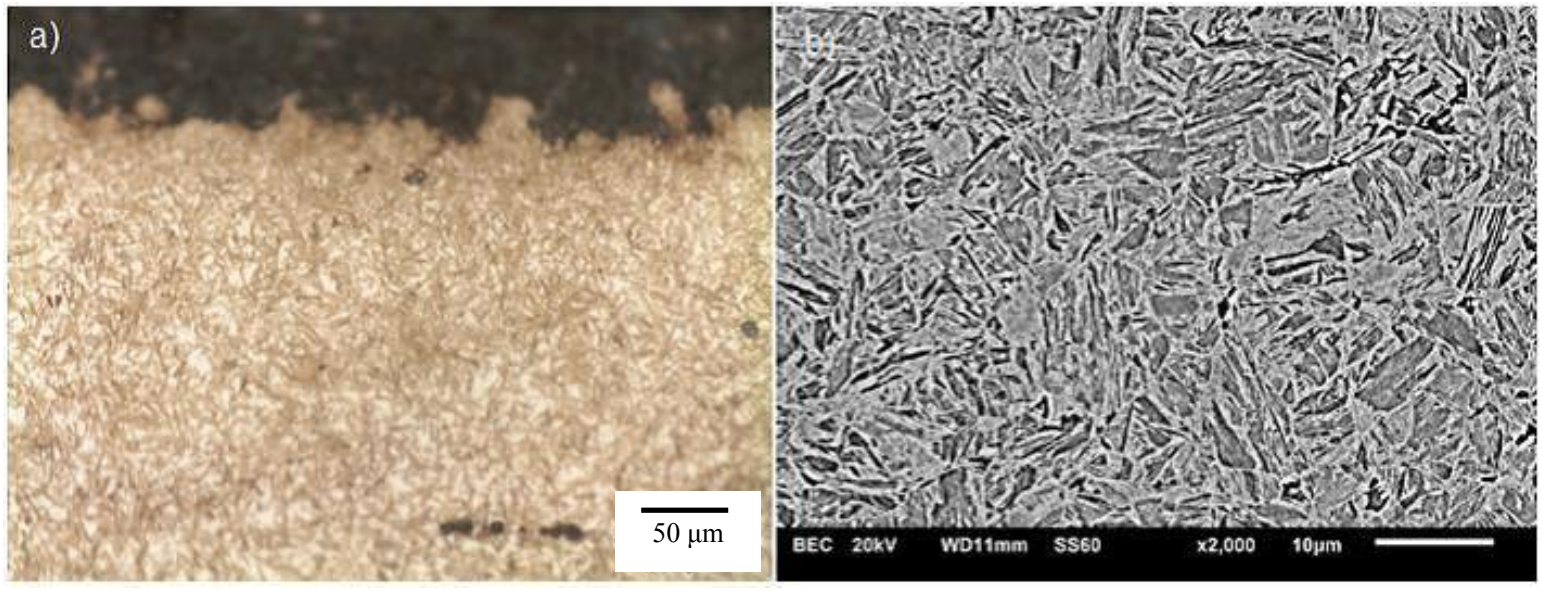

Figura 4: Microestrutura da camada cementada (a) MO e (b) MEV. 
A Figura 5 mostra as imagens utilizadas no programa Phase Analysis para análise da fase austenítica e determinação do percentual da austenita retida.

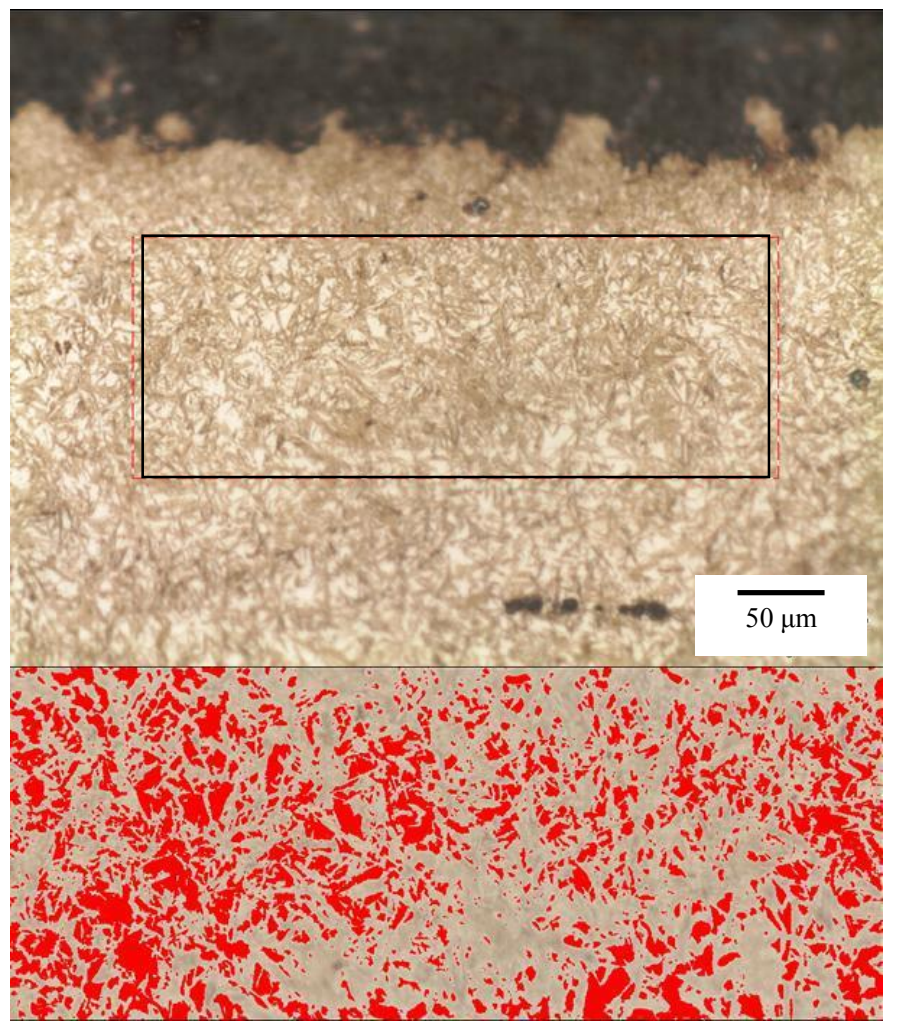

Figura 5: Microestrutura do aço cementada (parte superior) e com programa Phase Analysis (parte inferior).

A presença de austenita retida tem forte influência do potencial de carbono e da presença de elementos de liga $[8,9,16]$. A austenita retida pode ser fator deletério aos componentes devido ao fato do mesmo poder transforma-se em martensita não revenida por processo mecânico [17]. Se não for posteriormente revenida poderá fragilizar o material $[9,16]$.

Foi encontrada microestrutura martensitica e presença de austenita retida, não sendo detectado crescimento anormal de grão nas amostras, após a cementação e tratamento térmico. A presença de austenita retida ocasionou variações microestruturais, junto a superfície das amostras cementadas associando-se este fato a utilização de potencial de carbono elevado na atmosfera gasosa.

As amostras de aços DIN 20MnCr5 apresentaram percentual médio de 32,32\% de austenita retida.

\subsection{Análise microestrutural das amostras para o processo de shot peening dinâmico}

A Figura 6 apresenta as imagens obtidas por microscopia ótica e microscopia eletrônica de varredura após processo de shot peening dinâmico.
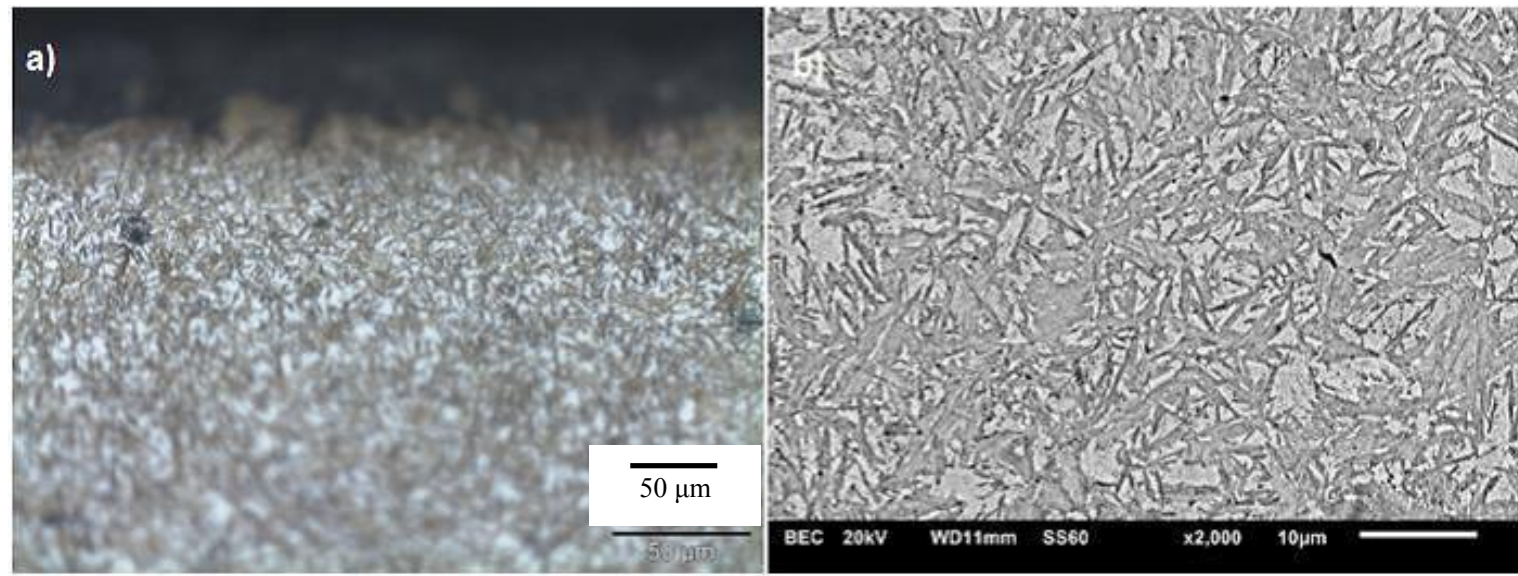
Figura 6: Microestrutura após processo de shot peening dinâmico (a) MO e (b) MEV.

Na Figura 7 pode ser visualizadas imagens do programa Phase Analysis para análise da fase austenítica e determinação do percentual da austenita retida.

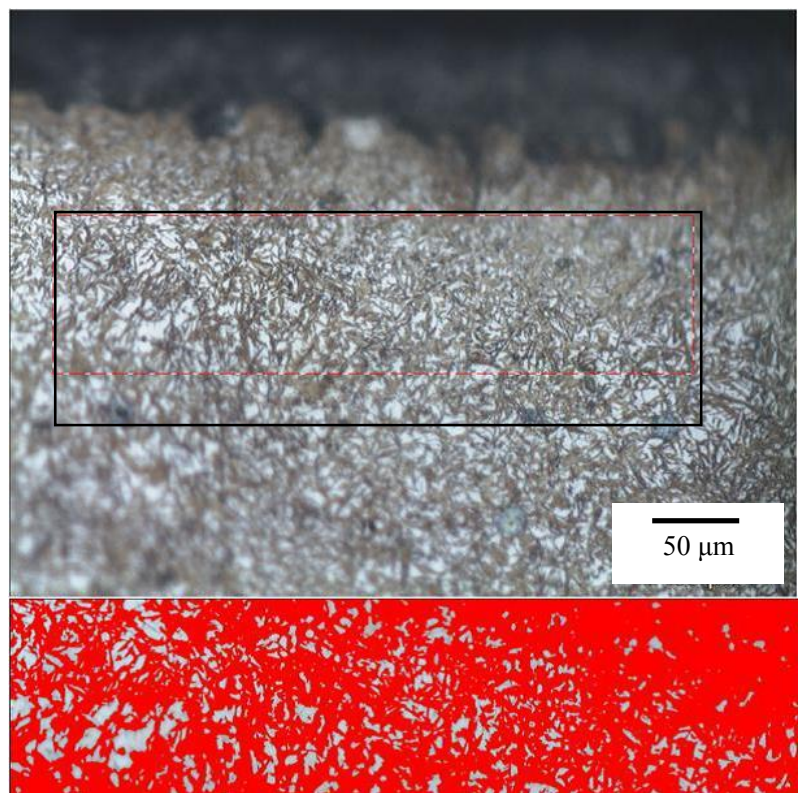

Figura 7: Microestrutura do aço após shot peening dinâmico (parte superior) e com programa Phase Analysis (parte inferior).

Não foram detectadas micro trincas nas amostras que receberam o processo shot peening dinâmico. Não foram detectados carbonetos em contornos de grão, após a aplicação do referido processo mecânico.

O percentual de austenita retida na superfície da camada cementada após o processo de shot peening em sistema rotativo (dinâmico) sofreu uma redução de 32,32\% para 22,1\%. Este resultado se deve provavelmente a colisões das microesferas com a superfície da peça proporcionando energia mecânica suficiente para que ocorra a transformação da austenita retida em martensita, com intensidade da carga aplicada a esta transformação ocorrendo e pela deformação plástica (martensita de deformação) resultante do processo [1].

\subsection{Análise microestrutural das amostras para o processo de shot peening estático}

A Figura 8 exibe as imagens obtidas em MO e MEV, bem como a espessura da camada afetada no processo. 


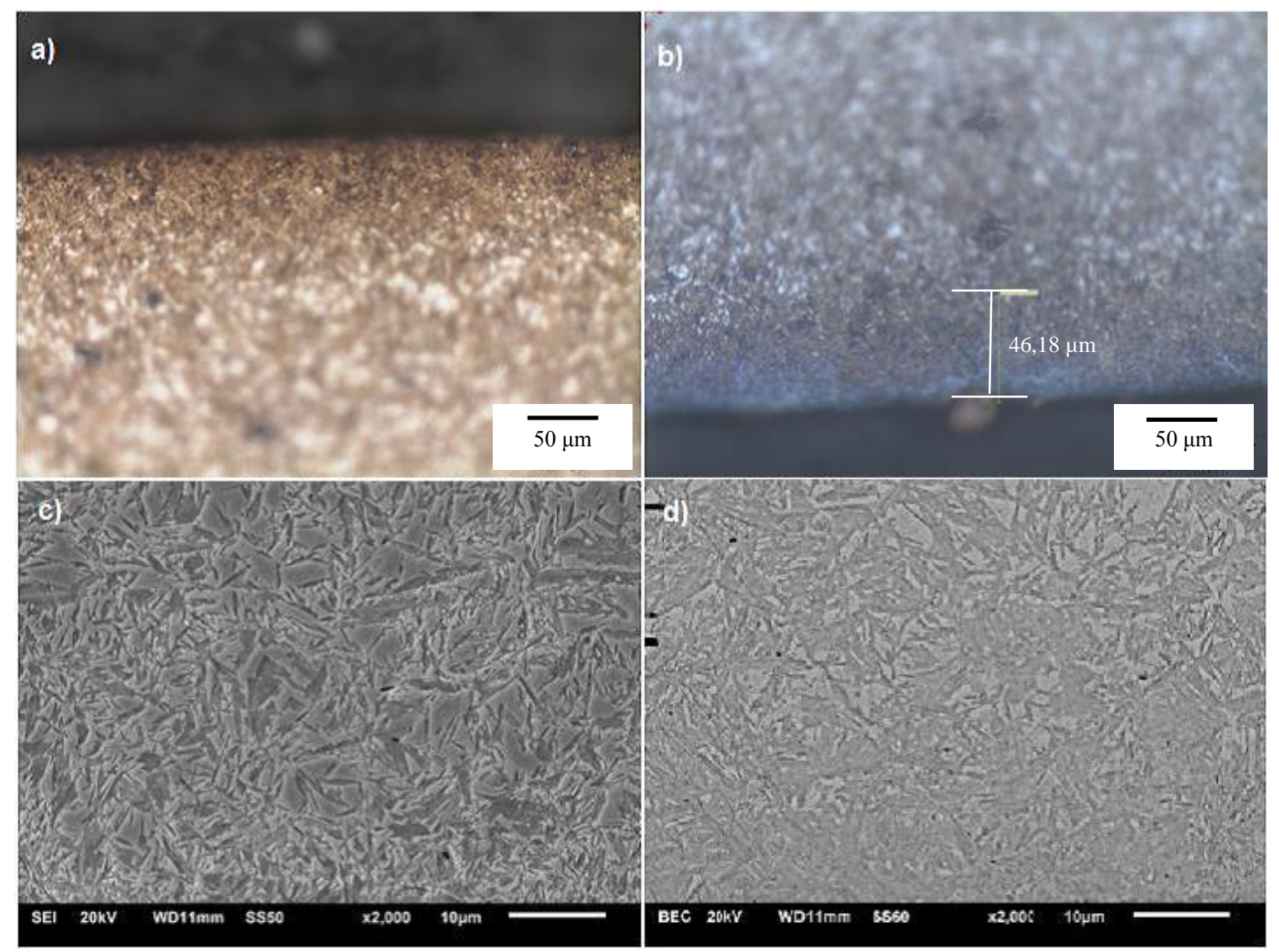

Figura 8: Microestrutura da superfície onde ocorreu a transformação a) MO, b) da espessura, c) e d) MEV

A transformação da austenita retida em martensita ocorreu quase que total em uma região bem superficial, com profundidade de 46,18 $\mu$ m na camada cementada, decorrente da intensidade de deformação aplicada no processo.

A Figura 9 detalha as imagens do programa Phase Analysis para análise da fase austenítica e determinação do percentual da austenita retida. 


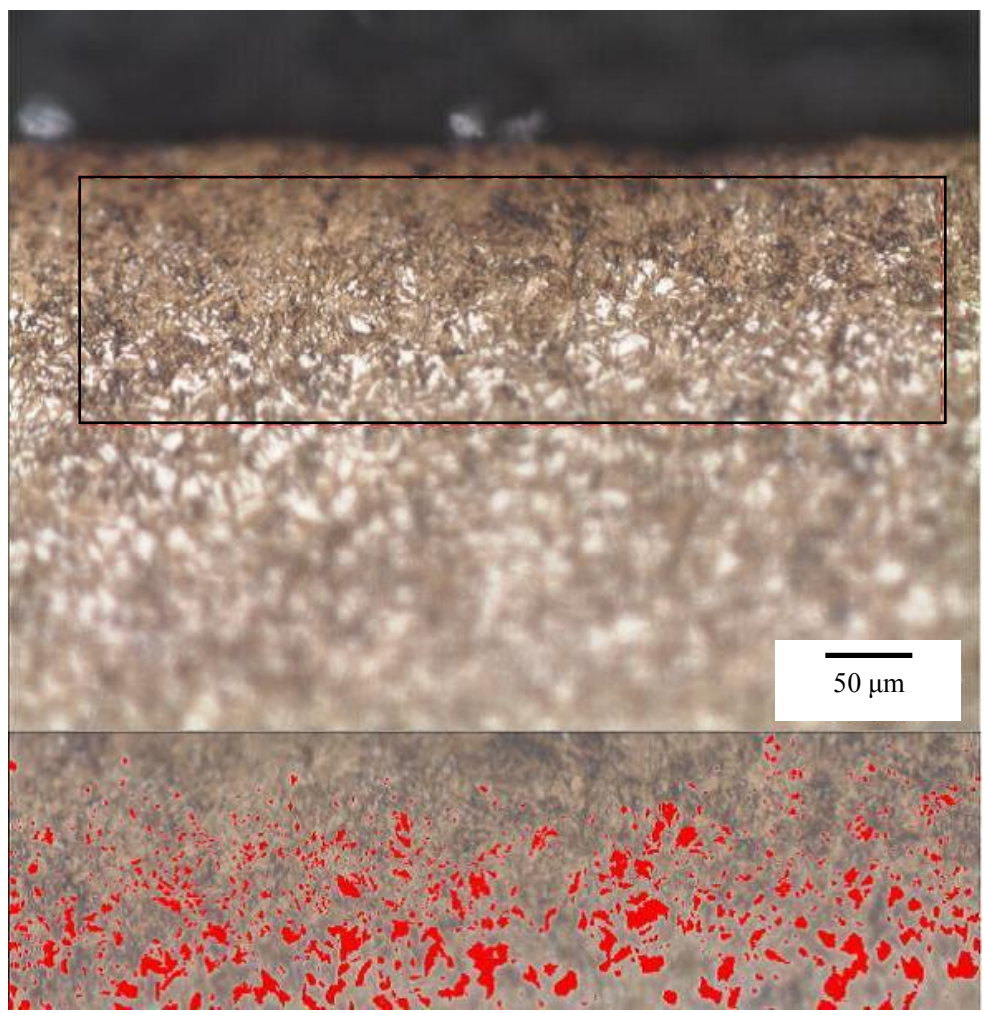

Figura 9: Microestrutura do aço cementada após shot peening estático (parte superior) e com programa Phase Analysis (parte inferior).

Também não foram detectadas micro trincas nas amostras que receberam o processo de shot peening estático. Não foram detectados carbonetos em contornos de grão, após a aplicação dos processos mecânicos.

Os percentuais de austenita retida no processo de shot peening estático bem como a região selecionada no programa mostraram uma redução na austenita retida de 32,32\% para 6,04\%. Este resultado se deve provavelmente característica do processo, já que neste caso, a amostra permanece o tempo todo estática, recebendo a colisões das microesferas com a superfície da peça e ocasionando uma maior deformação plástica e consequentemente maior energia para que ocorra a transformação da austenita retida em martensita [1].

\subsection{Ensaio de microdureza}

\subsubsection{Aços DIN 20MnCr5 cementado e tratado termicamente}

A Figura 10 apresenta os resultados obtidos dos testes de microdureza das amostras após a cementação, têmpera e posterior revenimento. 
a)

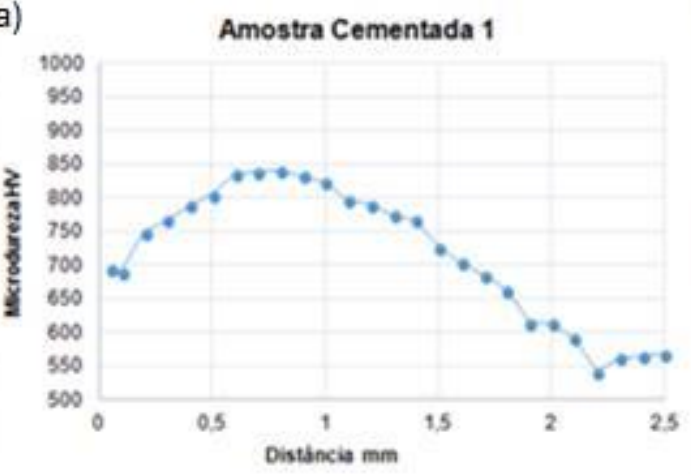

c)

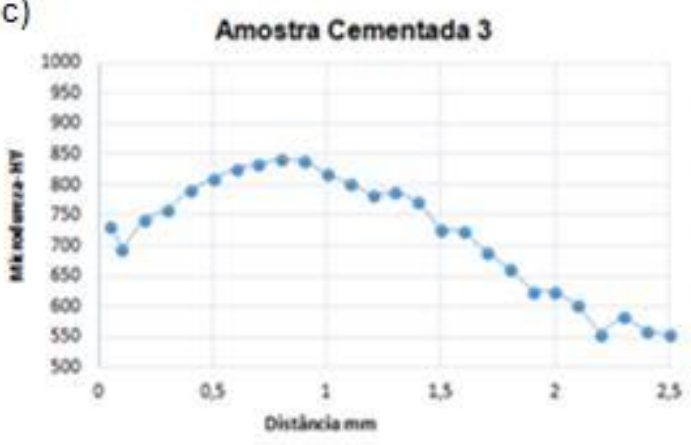

b)

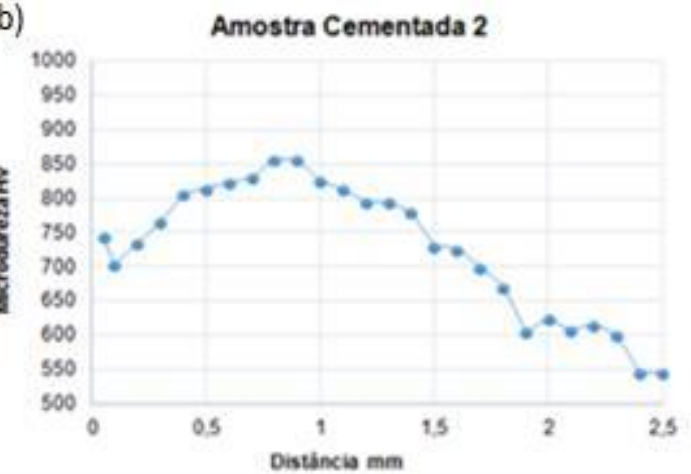

d)

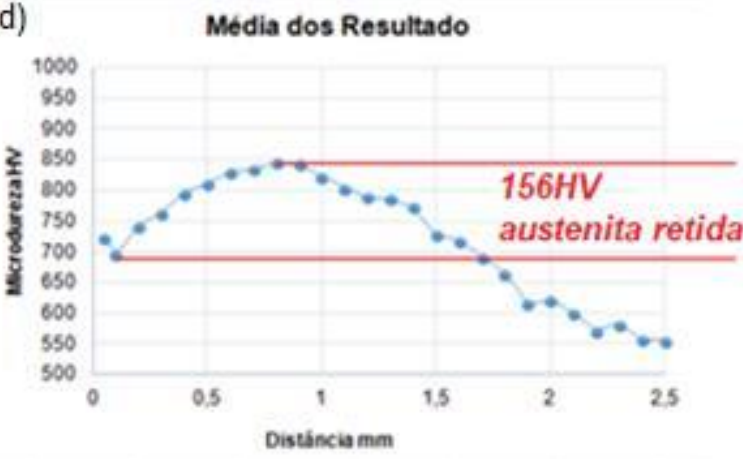

Figura 10: Representação gráfica da microdureza das amostras cementadas e tratadas termicamente

Os resultados obtidos através de gráficos demonstram que a resultados de microdureza começam de forma crescente até atingirem seu resultado máximo $(846 \mathrm{HV})$ com profundidade $0,8 \mathrm{~mm}$.

A variação da microdureza $(156 \mathrm{HV})$ mostrada no gráfico (indicada pela menor amplitude entre o mínimo inicial e a máxima dureza) ocorre pela estabilidade da austenita com o aumento dos teores de carbono devido a cementação. O carbono em solução sólida contribui aumentando a resistência ao cisalhamento da austenita, desse modo, quantidades apreciáveis de austenita não se transformaram, estando presentes entre as ripas de martensita a temperatura ambiente $[9,16]$.

\subsubsection{Microdureza para o processo de shot peening dinâmico}

A Figura 11 exibe os resultados obtidos dos testes de microdureza das amostras submetidas ao processo de shot peening dinâmico. 
a)
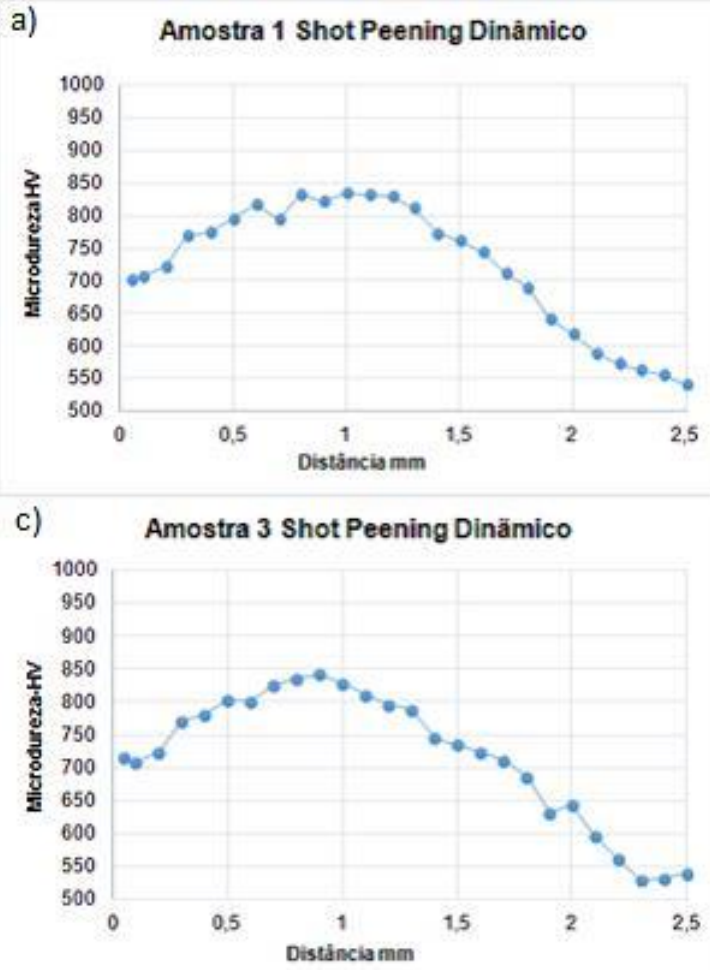

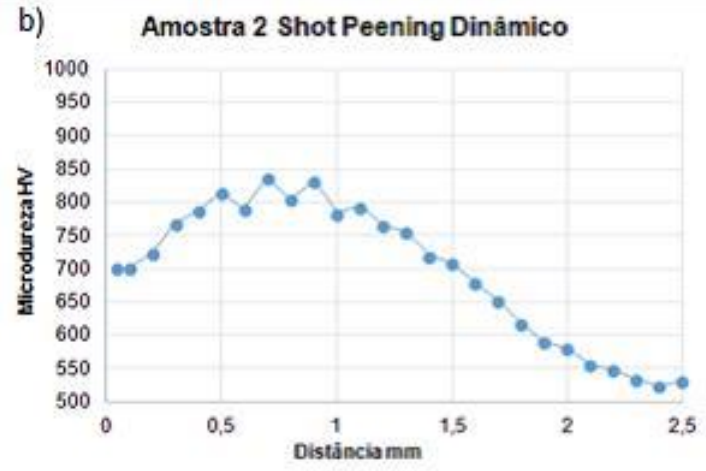

d)

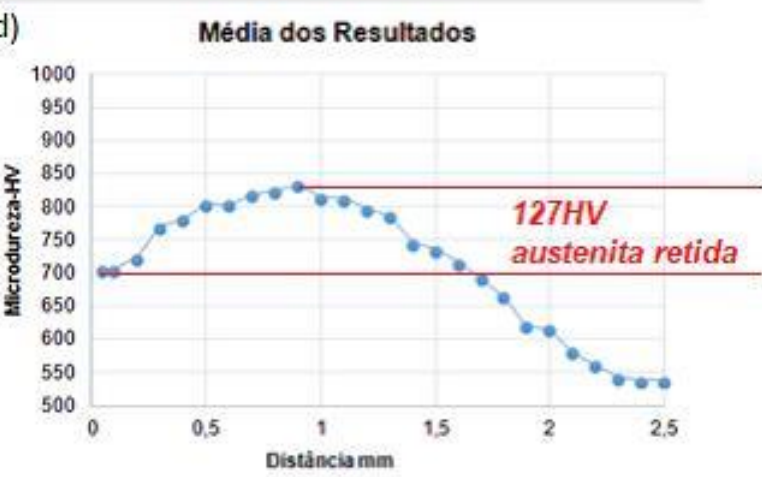

Figura 11: Representação gráfica da microdureza das amostras do processo de shot peening dinâmico

Como pode ser observado nos gráficos houve uma diminuição no valor de austenita retida, comparado com as amostras de referência, de $156 \mathrm{HV}$ para $127 \mathrm{HV}$. Os ensaios de microdureza corroboram e confirmam os resultados obtidos na análise microestrutural demonstrando a eficácia da utilização do processo de shot peening para esta aplicação.

\subsubsection{Microdureza para o processo de shot peening estático}

A Figura 12 expressa os resultados obtidos dos testes de microdureza das amostras submetidas ao processo de shot peening estático. 

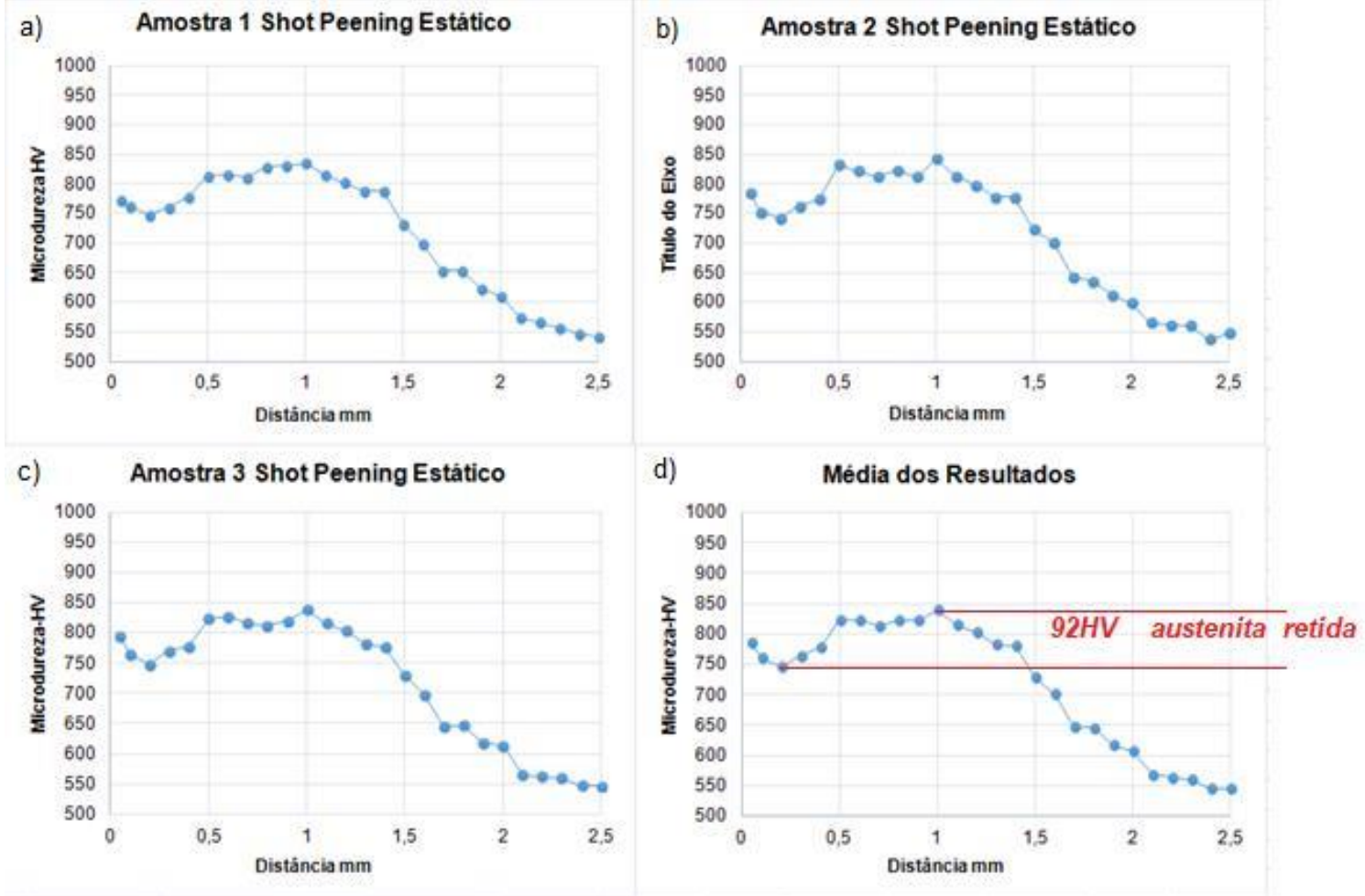

Figura 12: Representação gráfica da microdureza das amostras do processo de shot peening estático

Como pode ser observado nos gráficos houve uma diminuição maior ainda no valor de austenita retida, comparado com as amostras de referência, de $156 \mathrm{HV}$ para $92 \mathrm{HV}$ no caso do shot peening estático.

Conforme já havia se discutido na seção que trata da análise microestrutural do shot peening estático, este resultado também pode ser atribuído ao processo em que a amostra permanece o tempo todo estática, recebendo a colisões das microesferas com a superfície da peça e ocasionando uma maior deformação plástica [1].

\section{CONCLUSÕES}

Os resultados indicaram que a aplicação dos processos mecânicos de shot peening se apresentou com uma técnica confiável para transformação da austenita retida em martensita, melhorando o desempenho de componentes cementados. Dentre estes processos o de shot peening estático foi o que apresentou melhor rendimento com valores de percentual de austenita retida de 6,04\% e microdureza de $92 \mathrm{HV}$.

Os resultados são coerentes com os encontrados na literatura e contribuem para que esta técnica possa ser utilizada no intuito de proporcionar um material com menor índice de falha. Diante disto, cabe salientar a importância da continuidade dos estudos de pesquisa e inovação de processos que visem a transformação da austenita em materiais que possuem características que possibilitem a utilização deste tipo de metodologia.

\section{AGRADECIMENTOS}

Os autores deste trabalho agradecem a CAPES, FAPERGS e CNPq pelo suporte financeiro.

\section{BIBLIOGRAFIA}

[1] PERLADE, A.; BOUAZIZ, O.; FURNÉMONT, Q. “A physically based model for TRIP-aided carbon steels behaviour", Materials Science and Engineering A, v. 356, n. 1, pp. 145-152, Sep. 2003.

[2] COMMITTEE ON GAS CARBURING, "Carburing and carbonitriding". American Society for Metals, USA, 1977.

[3] KRAUS, G. "Steels: Heat treatment and processing principles", Heat Treating, American Society for Metals International Handbook, Volume 4, USA, 1991. 
[4] MEDEIROS, J. L. B.; REGULY, A.; STROHAECKER, T. R. “Applying Oxi-nitrocarburizing surface strengthening process to corrosion prevention in MIM 17-4 PH stainless steel”, Espacios (Caracas), v. 36, pp. 21-26, 2015.

[5] KRAUSS, G.; "Microstructure and properties of carburized steels", Heat Treating, American Society for Metals International Handbook, Volume 4, USA, 1991.

[6] VIEIRA, E. R.; BIEHL, L. V.; MEDEIROS, J. L. B.; SILVA, A. B.; SILVA, M. S. "Efeitos da variação da concentração de solução polimérica aquosa a base de PVP na têmpera de aço AISI 4140", Revista Matéria, v. 24, pp. 1-11, 2019.

[7] VIEIRA, E. R.; BIEHL, L. V.; MEDEIROS, J. L. B.; COSTA, V. M.; MACEDO, R. J. "Evaluation of the characteristics of an AISI 1045 steel quenched in different concentration of polymer solutions of polyvinylpyrrolidone", Scientific Reports, v. 11, pp. 1313-1321, 2021.

[8] OLIVEIRA, R. C. L. M.; BIEHL, L. V.; MEDEIROS, J. L. B.; FERREIRA FILHO, D.; SOUZA, J. D. "Análise comparativa entre a têmpera e partição versus a têmpera e revenimento para o aço SAE 4340", $R e$ vista Matéria, v. 24, pp. 1-11, 2019.

[9] HU, Z. Z., MA, M. L., LIU, Y.Q. et al.., "The effect of austenite on low cycle fatigue in three-phase steel”, International Journal of Fatigue, v. 19, n. 8-9, pp. 641-646, 1997.

[10] ZAEFFERER, S.; OHLERT, J.; BLECK, W. "A study of microstructure, transformation mechanisms and correlation between microstructure and mechanical properties of a low alloyed TRIP steel", Acta Materialia, v. 52, pp. 2765,-2778, Apr. 2004.

[11] YAN, Y. H.; KAI, G. Y.; JIAN, M. D. "Transformation behavior of retained austenite under different deformation modes for low alloyed TRIP-assisted steels", Materials Science and Engineering A, v. 441 n. 12, pp..331-335, Dec. 2006.

[12] PFEIFFER, W., FREY, T. "Strengthening of ceramics by shot peening", Journal of the European Ceramic Society, v. 26, n. 13, pp. 2639-2645, 2006

[13] TORRES, M. A. S., "Uma avaliação do efeito do shot peening na vida em fadiga do aço ABNT 4340 com e sem revenimento de cromo duro", Tese de D.Sc., FEG/UNESP, Guaratinguetá, SP, Brasil, 2002.

[14] TAMURA, I. "Deformation-induced martensitic transformation and transformation-induced plasticity in steels", Metal Science, v. 16, pp. 245-253, 1982.

[15] COMMITTEE ON ASM METALS HANDBOOK, "Friction, lubrication and wear technology", ASM International, v. 18, USA, 2017.

[16] HIDALGO, J., FINDLEY, K. O., SANTOFIMIA, M. J. Thermal and mechanical stability of retained austenite surrounded by martensite with different degrees of tempering, v. 690, pp. 337-347, Apr. 2017.

[17] NISHYAMA, Z. Martensitic transformation, $1^{\circ}$ ed., New York, Academic Press, 1978.

\section{ORCID}

Marcelo Gautério Fonseca https://orcid.org/0000-0002-1702-432X

Leandro Macedo Cozza $\quad$ https://orcid.org/0000-0002-2312-7683

Jorge Luis Braz Medeiros https://orcid.org/0000-0003-3468-7632

Sérgio da Silva Cava https://orcid.org/0000-0002-0907-7739 